This item was submitted to Loughborough's Research Repository by the author.

Items in Figshare are protected by copyright, with all rights reserved, unless otherwise indicated.

\title{
Generation of higher harmonics in longitudinal vibration of beams with breathing cracks
}

\section{PLEASE CITE THE PUBLISHED VERSION}

http://dx.doi.org/10.1016/j.jsv.2016.06.025

\section{PUBLISHER}

(C) Elsevier

\section{VERSION}

AM (Accepted Manuscript)

\section{PUBLISHER STATEMENT}

This work is made available according to the conditions of the Creative Commons Attribution-NonCommercialNoDerivatives 4.0 International (CC BY-NC-ND 4.0) licence. Full details of this licence are available at: https://creativecommons.org/licenses/by-nc-nd/4.0/

\section{LICENCE}

CC BY-NC-ND 4.0

\section{REPOSITORY RECORD}

Broda, D., L. Pieczonka, Vikrant Hiwarkar, W. Staszewski, and Vadim Silberschmidt. 2016. "Generation of Higher Harmonics in Longitudinal Vibration of Beams with Breathing Cracks". Loughborough University. https://hdl.handle.net/2134/23652. 


\title{
Generation of higher harmonics in longitudinal vibration of beams with breathing cracks
}

\author{
D. Broda ${ }^{a}$, L. Pieczonka ${ }^{a}$, V. Hiwarkar ${ }^{b}$, W.J. Staszewski ${ }^{a, *}$, V.V. Silberschmidt ${ }^{b}$ \\ ${ }^{a}$ Department of Robotics and Mechatronics, AGH University of Science and Technology, Al. A. Mickiewicza, 30-059 Krakow, Poland ${ }^{\mathrm{b}}$ Wolfson \\ School of Mechanical and Manufacturing Engineering, Loughborough University, Loughborough, Leicestershire LE11 3TU, UK
}

\section{A B S T R A C T}

\begin{abstract}
Classical nonlinear vibration methods used for structural damage detection are often based on higher- and sub-harmonic generation. However, nonlinearities arising from sources other than damage - e.g. boundary conditions or a measurement chain - are a primary concern in these methods. This paper focuses on localisation of damage-related nonlinearities based on higher harmonic generation. Numerical and experimental investigations in longitudinal vibration of beams with breathing cracks are presented. Numerical modelling is performed using a two-dimensional finite element approach. Different crack depths, locations and boundary conditions are investigated. The results demonstrate that nonlinearities in cracked beams are particularly strong in the vicinity of damage, allowing not only for damage localisation but also for separation of crack induced nonlinearity from other sources of nonlinearities.
\end{abstract}

\author{
Keywords: \\ Nonlinear dynamics \\ Longitudinal vibration of beams \\ Breathing crack \\ Crack detection \\ Crack localization
}

\section{Introduction}

A growing complexity of modern civil, aerospace and power-plant structures has led to development of more strict safety regulations. In order to meet these strict regulations, reliable and cost-effective maintenance methods are required. Effective maintenance not only improves safety, but also minimises the cost of ownership and mitigates unnecessary repairs. It is well known that Non-Destructive Testing (NDT) is the field of engineering that addresses this important problem, assuring the desired level of safety [1]. NDT inspections are, however, performed only at predefined time intervals and are often not sufficient to capture the evolution of damage in monitored structures. Hence, the more recent Structural Health Monitoring (SHM) approach is based on permanently mounted (bonded or embedded) networks of sensors used for continuous monitoring of structures [2,3]. Among the many available approaches to SHM, methods based on nonlinear vibration/ acoustic phenomena are of special interest, gaining an increasing attention in the scientific community [4-6]. This is mainly due to the fact that the nonlinear damage detection methods are usually more sensitive to detect small damage severities than their linear counterparts [7-9].

Structural damages (e.g. cracks or delaminations) affect modal parameters, i.e. natural frequencies, damping and mode shapes of monitored structures $[10,11]$. Therefore, vibration-based damage detection methods monitor these parameters and relate them to possible structural damage. It is well known from theory that cracks in beams reduce stiffness locally, leading to the reduction of lower order natural frequencies. This observation leads to various open-crack formulations, in

\footnotetext{
* Corresponding author.

E-mail addresses: dbroda@agh.edu.pl (D. Broda), staszews@agh.edu.pl (W.J. Staszewski).
} 
which structural stiffness is decreased regardless of loading. However, in real engineering structures that are vibrated cracks remain open only when static stresses are significantly high. Otherwise cracks can easily close during compression and open during tension within one vibration cycle [11]. This opening-closing nonlinear crack effect - often referred to as breathing crack - has attracted many research investigations since the early work from the 1980s [12,13]. Various analytical, numerical and experimental studies have been performed including the work presented in [11,14-16]. The effect of open and closed cracks on natural frequencies of beams was investigated in $[12,13,17-20]$. A frequency drop was shown to be smaller for breathing - rather than for open - cracks in these investigations.

The simplest model of a breathing crack utilises a bi-linear stiffness relation that uses different elastic moduli for the open and closed crack:

$$
m \ddot{q}+c \dot{q}+k(q) q=F(t)
$$

where $m$ stands for mass, $c$ denotes damping, $F$ is a time-dependent excitation force and stiffness $k(q)$ can be modelled as

$$
k(q)= \begin{cases}k_{t} & \text { if } q \geq q_{0} \\ k_{c} & \text { if } q<q_{0}\end{cases}
$$

and $q$ denotes the crack response, $q_{0}$ is the value of the response when the crack opens or closes, $k_{c}$ and $k_{t}$ stand for stiffnesses for closed and open crack, respectively. More accurate physical models also involve the contact of crack edges (or faces) at non-zero velocities (contact of rough surfaces), crack-tip plasticity, friction and even temperature gradients near crack tips [21].

The analysis of higher harmonics is a possible solution to the problem of minor frequency drop related to damage $[11,16,22-25]$. Some of the signal processing techniques applied for higher harmonics analysis are based on the bi-spectrum [26,27], time-frequency analysis [28,29] and higher order transfer function [24]. The influence of damping on the level of nonlinearities in cracked structures and the analysis of pseudo-superharmonic resonances were investigated in [30]. Other damage indicators based on higher harmonic generation involve the application of the nonlinear output frequency response functions (NOFRFs) [31], Volterra-series response representation [32] and the multi-modal technique [33]. The latter method assumes that individual vibration modes are sensitive to different crack locations. This assumption can be used for precise location of small defects (crack depth proportional to 10 percent of specimen cross-sections). Higher harmonics in ultrasonic responses were also investigated for damage detection, e.g. in [34]. Several FE models of beam with breathing crack were presented in the literature. 2-D and 3-D frictional FE models of cracked beam were presented in [35,36]. The work involved parametric studies of the effect of crack depth, position and angle on natural frequencies of a beam. Several different configurations of cracks and positions of applied forces were investigated in [37]. The study based on a 3-D FE model of cracked beams investigated changes in natural frequencies resulting from both free and forced vibration. Not only $\mathrm{FE}$, but also other techniques, like spectral elements method, were proposed for simulations of damage detection in cracked structures [38].

A 2-D FE model of beam with a breathing crack was investigated in [39-41]. The excitation frequency corresponded to harmonics and sub-harmonics of the natural frequency of the beam. Crack detection approaches based on amplitudes of higher harmonics and sub-harmonics, excursion variations and trajectory eccentricities of the phase portrait were proposed. Vibration responses measured at various locations on the beam in experimental studies demonstrated that sensor location and excitation amplitude had a negligible effect on crack detection.

It appears that nonlinear longitudinal vibration of cracked beams has attracted less research effort. Longitudinal vibration of bar with breathing cracks were investigated in a series of publications [42-44]. The dynamic compliance (receptance) is modelled in these investigations as [42]

$$
L_{l}(l, j \omega)=\frac{l}{E S \xi}\left[\tan \xi-\frac{\mathrm{j} X}{4 \pi} \frac{\xi+\frac{1}{2} \sin (2 \xi)}{\cos ^{2} \xi}\right]
$$

where $\xi=\frac{\omega l}{\gamma}, \gamma=(E / \rho)^{(1 / 2)}, l, S$ and $E$ are the length, cross-sectional area and modulus of elasticity of the bar, respectively, $\omega$ is the frequency of excitation and $X$ stands for the absorption coefficient. This equation was transformed using a general linear theory of integral equations for straight rods, allowing for numerical simulations based on the Matlab-Simulink environment [42]. The analytical and numerical studies were validated by a series of experiments that utilised cracked aluminium samples [43]. The results of simulations demonstrated generation of higher harmonics and a decrease of natural frequencies. These nonlinear effects were dependent on crack parameters. The results also demonstrated that the intensity of higher harmonics was a function of a distance between a response location and a crack location [43]. The conclusions on the relation between these locations was rather general, and based on tests performed for simple experimental arrangements. It is also important to note that numerical simulations, demonstrating the existence of the crack localisation effect, were conducted only for a 1-D model in the Matlab Simulink environment. The term crack localisation effect refers to the local increase of a nonlinearity near the crack.

The crack localisation effect was also mentioned by other authors. Experimental studies in [45-47] indicate that the amplitude of the second harmonic is particularly strong near impact damage in composite plates. However, this effect was 


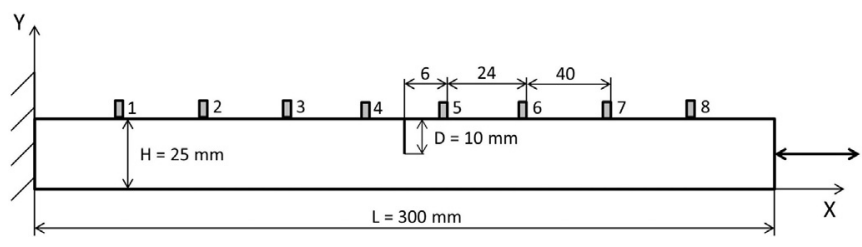

Fig. 1. Schematic diagram of cracked beam with indicated positions of sensors.

only investigated experimentally. According to the authors knowledge there was no attempt to investigate the effects of crack depth and position on the crack localisation effect in beams using FE simulations.

This paper investigates longitudinal vibrations in beams with breathing cracks. The major focus in these investigations is on a local increase of amplitude of higher harmonics near the crack location, i.e. the crack localisation effect. Finite Element modelling is used to study higher harmonics generation and spatial distribution in cracked beams. Even though numerous nonlinear crack models were described in the literature [48] the crack-induced growth of nonlinearity was not investigated numerically. This paper aims to fill this gap. Three most frequently used crack models are investigated, namely (1) higher terms in elastic moduli, (2) bi-linear stiffness and (3) breathing crack. In these numerical investigations the distribution of higher harmonics along the beam is studied for each model. The effect of depth, position and orientation of a single crack and multiple cracks is investigated. The effect of friction coefficient, contact stiffness and sensor location is analysed. Numerical simulations are validated experimentally on a set of test samples. In order to address the problem of intrinsic nonlinearities, i.e. not related to damage, the fixed-free and free-free Boundary Conditions (BC) are investigated. This paper attempts to answer three important questions: (1) Is it feasible to reliably detect, localise and assess the depth of a crack by the analysis of higher harmonics? (2) If yes, which is the best position to measure nonlinear responses for crack detection? (3) Could the damage-induced growth of nonlinearity be explained via simple crack models?

\section{Numerical models of cracked beams}

\subsection{Finite element model of beams with cracks}

A structure investigated was a $300 \times 25 \times 10 \mathrm{~mm}$ cantilever aluminium beam, as shown in Fig. 1. A harmonic force was applied to a free end of the beam. The excitation frequency of $4248 \mathrm{~Hz}$ used corresponded to beam's first longitudinal vibration mode. A response of the beam was investigated using the FE model developed in ABAQUS. Five different crack locations in the beam were investigated, from the minimum distance of $50 \mathrm{~mm}$ to the maximum distance of $250 \mathrm{~mm}$ from the free end of the beam. Numerical simulations also involved three different crack depths: 4,6 and $8 \mathrm{~mm}$. The deepest crack investigated corresponded approximately to the $1 / 3$ of the thickness of the beam.

Vibration responses were analysed at eight different locations alongside the beam, as shown in Fig. 1. It is important to note that all positions for sensors were fixed with respect to the crack positions. Pairs of sensors were located 6, 30, 70 and $110 \mathrm{~mm}$ to the left and right from the crack.

The beam was meshed with 2-D plane-stress CPS4R elements (4-node bilinear, reduced-integration with hourglass control). The CPS3 elements (3-node linear) were used in the case of slant cracks. The size of basic elements in the model was $2 \times 4 \mathrm{~mm}$. Smaller elements were employed to mesh the region around the crack. The area around the smallest $4 \mathrm{~mm}$ crack investigated was meshed to guarantee at least 10 nodes for each edge of the crack. The crack itself was modelled as a non-propagating seam crack, i.e. a face with overlapping nodes that can separate under dynamic loading applied. The meshed beam is shown in Fig. 2a and details of crack-tip meshing are presented in Fig. $2 \mathrm{~b}$ and $\mathrm{c}$ for the orthogonal and slant cracks, respectively. The contact between edges of the crack was simulated as a general contact, i.e. a penalty formula for the displacement between the faces of the crack was employed and friction was introduced using a classical isotropic Coulomb friction model.

Numerical simulation results from vibration analysis of cracked beams were post-processed in MATLAB. The time length of one simulated response was equal to $0.22 \mathrm{~s}$. The first $0.07 \mathrm{~s}$ was a transient response and thus disregarded. Since variable time stepping was involved, all the results were additionally linearly interpolated to achieve the final sampling frequency of $200 \mathrm{kHz}$. The spectral density investigated was equal to $7 \mathrm{~Hz}$. The main focus of the studies performed was on the level of nonlinearity associated with the generation of higher harmonics. This level of nonlinearity was investigated using amplitudes of higher harmonics estimated based on acceleration response spectra. In order to assess the level of nonlinearity for different parameters investigated, the amplitudes of higher harmonics were normalised with the amplitude of the fundamental frequency component. This resulted in the coefficients of nonlinearity defined as

$$
D_{i-1}=\frac{H_{i}}{A_{1}}
$$

where $A_{1}$ is the amplitude of the fundamental frequency component, $H$ is the amplitude of the generated higher harmonic and the subscripts $i=2,3$ indicate the second and third harmonics, respectively. The coefficients of nonlinearity based on the 
(a)

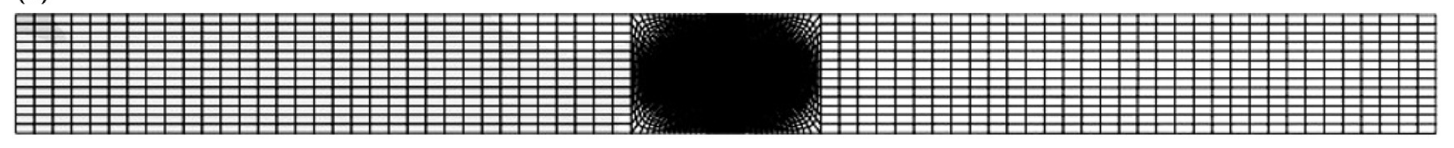

(b)

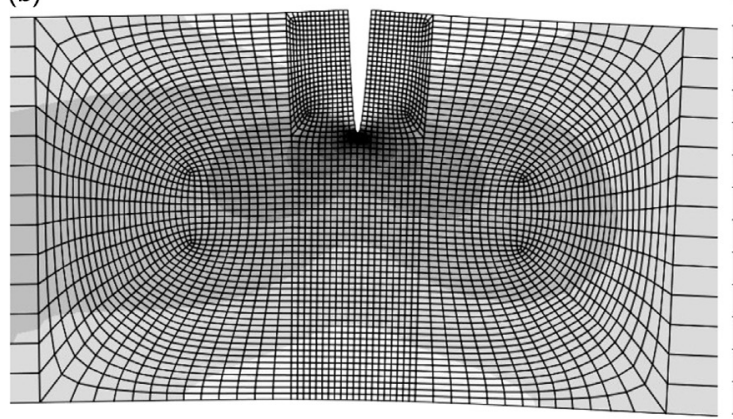

(c)

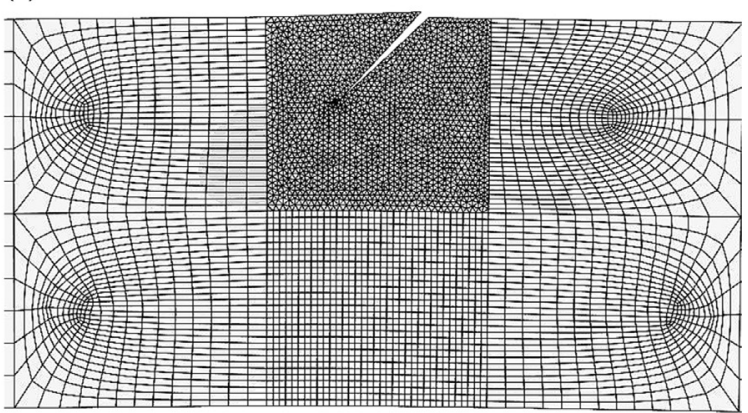

Fig. 2. Finite element model of cracked beam: (a) meshing of beam - general view; (b) zoomed mesh area around orthogonal crack; (c) zoomed mesh area around slant crack.

(a)

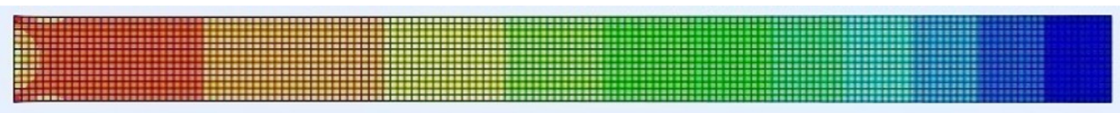

(b)

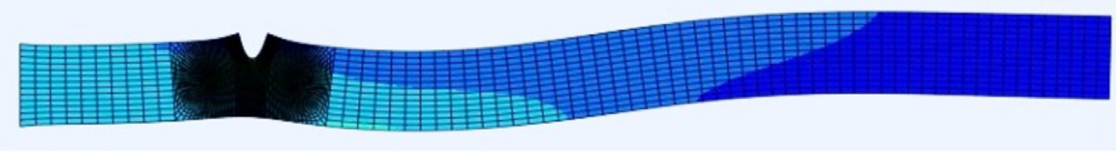

(c)

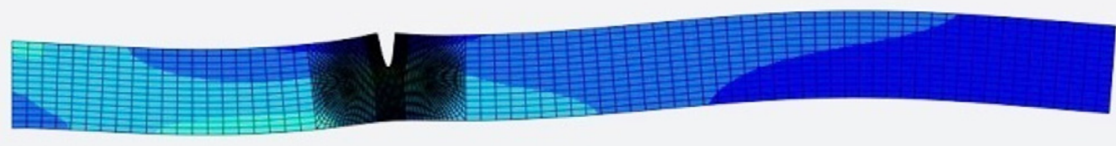

(d)

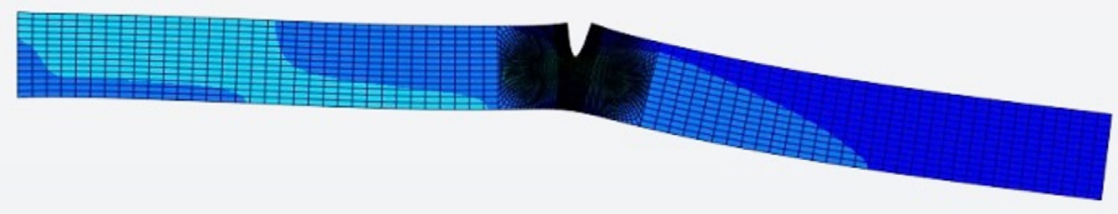

Fig. 3. Vibration mode shapes for: (a) intact beam; (b)-(d) cracked beams with surface cracks at different positions.

amplitude of the second $(i=2)$ and third $(i=3)$ harmonics will be referred to as the first and second coefficients of nonlinearity, respectively, throughout the paper.

\subsection{Linear vs. nonlinear vibration}

With the developed models of the cracked beam, numerical simulations were performed to obtain vibration mode shapes and vibration responses. This initial analysis was carried out to assess the model and confirm the nonlinear crackrelated behaviour of the beam.

\subsubsection{Vibration mode shapes}

The analysis of mode shapes was the first step in numerical simulations of the cracked beam. The results obtained for the intact and cracked beams are presented in Fig. 3. Since there is no crack in the intact beam the analysed mode shape is symmetrical with respect to its horizontal axis and, therefore, the longitudinal excitation applied leads to linear longitudinal 

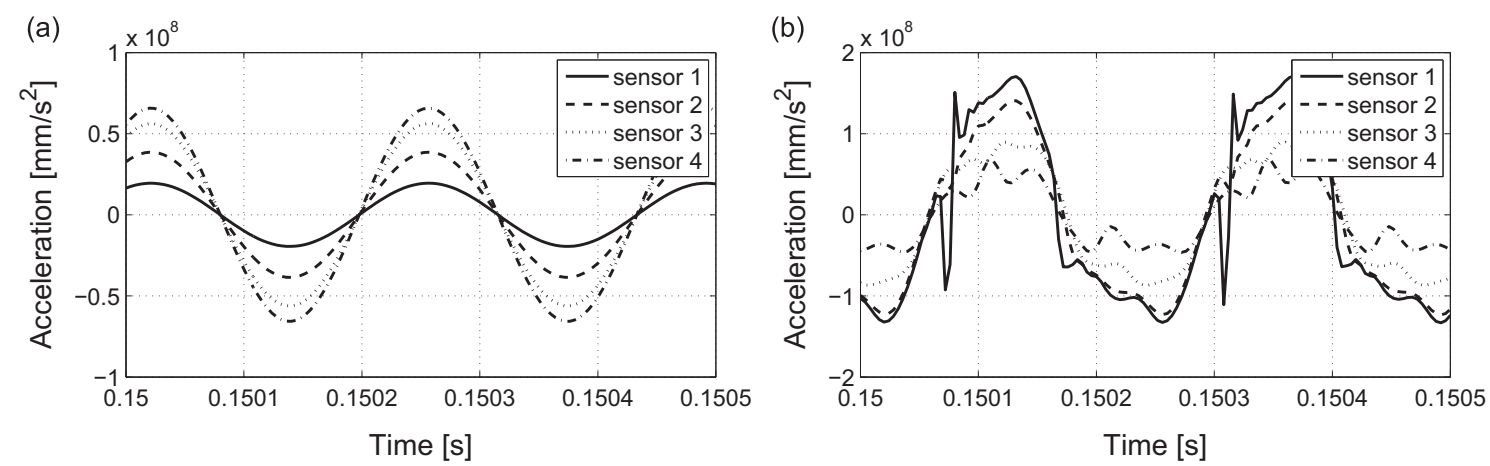

Fig. 4. Calculated vibration responses captured at four different locations alongside beam: (a) intact beam; (b) cracked beam.
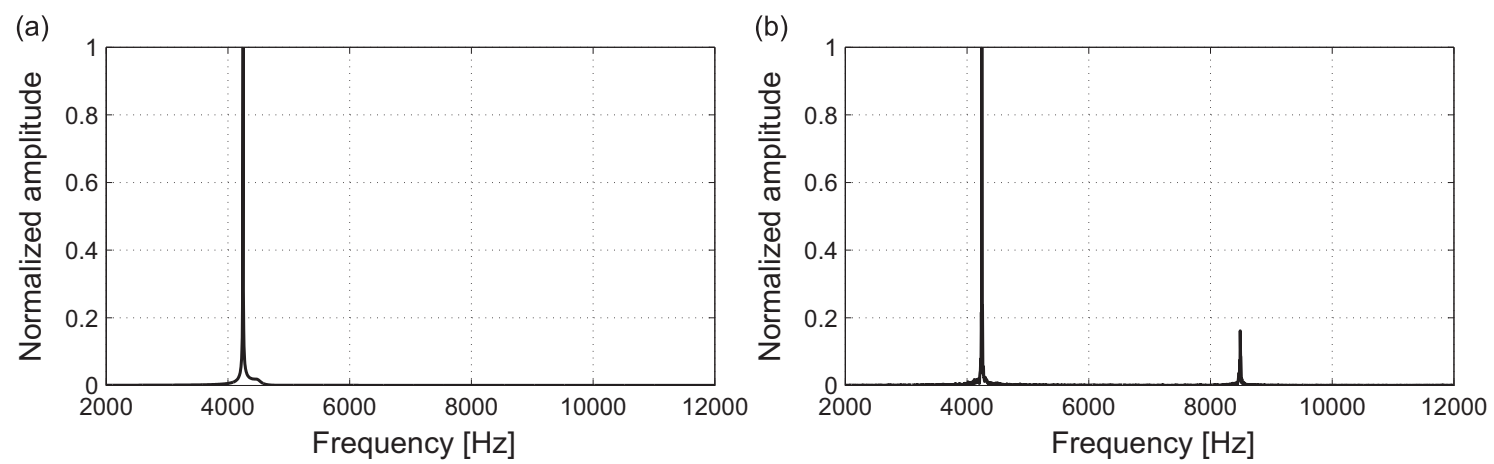

Fig. 5. Examples of power spectra calculated from vibration responses captured from sensor 3: (a) intact beam; (b) cracked beam. For sensors locations see Fig. 1.

vibration only, as demonstrated in Fig. 3a. The presence of crack breaks the symmetry, affecting mode shapes of the beam. Although the excitation is longitudinal, both longitudinal and transverse vibration can be observed, in the cracked beams, as demonstrated in Fig. $3 \mathrm{~b}-\mathrm{d}$. The results show that the analysed mode shapes depend strongly on the location of the crack, as expected.

\subsubsection{Vibration responses}

Time and frequency responses of the cracked beams were investigated in the next step. Time-domain vibration responses are presented in Fig. $4 \mathrm{a}$ and $\mathrm{b}$ for the intact and cracked beams, respectively. The crack investigated was 8 mm deep and located in the middle of the beam in these numerical simulations. The results in Fig. 4 are given for four different sensors that are located between the fixed end of the beam and the crack (see Fig. 1). Linear vibration responses (or, in other words, single harmonic waveforms) can be observed for the intact beam in Fig. 4a, as expected. The crack introduces nonlinear multi-harmonic responses, as shown in Fig. 4b; the amplitude levels of these responses depend on the distance between the excitation and measurement positions, as expected. This multi-harmonic (distorted) nature of responses can also be analysed in the frequency domain; Fig. 5 shows an example of two power spectra for the intact and cracked beam. The response data were captured by sensor 3. A clear pattern of higher harmonics can be observed in Fig. $5 \mathrm{~b}$ for the cracked beam, confirming the nonlinear behaviour.

\section{Longitudinal vibration of beams with cracks - numerical simulation results}

Once the nonlinear finite-element model of the cracked beam was built, numerical simulations were performed to investigate the nonlinear vibration response. The focus of these investigations was on the analysis of the amplitude of higher harmonics. This section presents the obtained results.

\subsection{Effect of excitation amplitude, contact stiffness and friction}

Firstly, the effect of excitation amplitude on the level of nonlinearity was investigated. The latter was assessed using the coefficient of nonlinearity defined by Eq. (4). Typical results for a $8 \mathrm{~mm}$-deep crack - located in the middle of the beam - are given in Fig. 6. The first (based on the amplitude of the second harmonic) and second (based on the amplitude of the third harmonic) coefficients of nonlinearity were calculated for three different amplitude levels of excitation force: $25 \mathrm{~N}, 125 \mathrm{~N}$ 
(a)

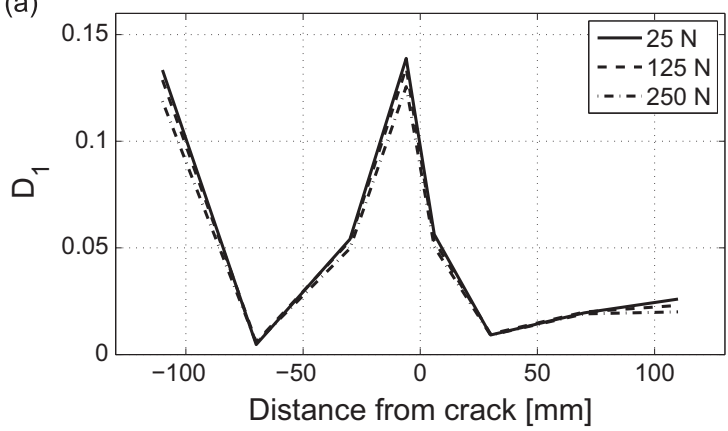

(b)

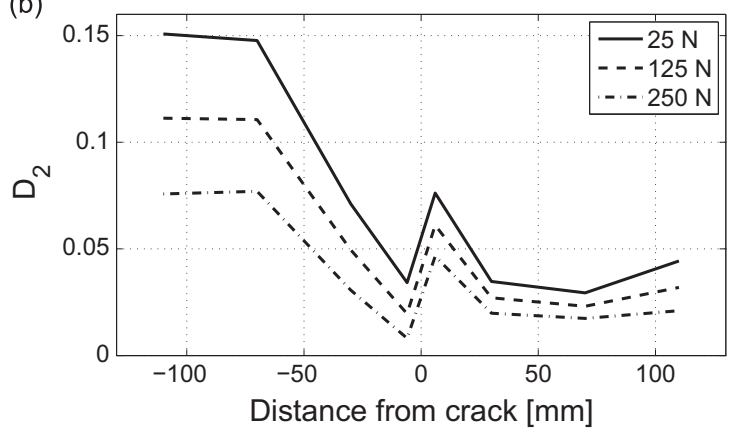

Fig. 6. Nonlinear coefficients for different amplitude levels of force excitation: (a) second harmonic; (b) third harmonic.

and $250 \mathrm{~N}$. The left and right ends of the horizontal axes correspond to the sensors closest to the fixed and free ends of the beam, respectively. Thus, a position on the axes of abscissa indicates a place of acquisition of the relevant responses with respect to the crack position. The value of zero corresponds to the crack position, and the magnitudes to the left and right from this origin indicate that responses were captured to the left and right from the crack location, respectively. All numerical simulation results are presented in this way throughout the paper.

Strong nonlinearities - exhibited by locally increased values of the coefficients of nonlinearity - can be observed near the fixed end of the beam and in the vicinity of the crack. The latter is visible particularly when the amplitude of the second harmonic is investigated in Fig. 6a. Additionally, the results in Fig. 6a show that the excitation amplitude has a negligible effect on the amplitude of the second harmonic. In contrast, the amplitude of the third harmonic is affected and increases with the amplitude level of excitation, as shown in Fig. 6 b.

The contact stiffness can be perceived as a spring, which links both crack faces that are in contact. A simple model of rough surfaces was also used to model friction between both faces of the crack. Thus, when ideal contact between parallel crack faces is maintained, no friction force is present. However, the results in Fig. 3 demonstrate that the crack introduces transversal vibrations even under longitudinal excitation. Numerical simulations performed showed that the effect of contact stiffness and friction - used in the model of the cracked beam - on the level of nonlinearity was negligible, i.e. no significant differences of the coefficients of nonlinearity were observed when these two parameters were investigated.

\subsection{Analysis of crack depth and position for orthogonal crack}

The effect of crack size on the level of nonlinearity was investigated for three different crack depths: 4, 6 and 8 mm. The results presented in Fig. 7 - for the crack located $250 \mathrm{~mm}$ from the free end of the beam demonstrate that the crack depth strongly affects the nonlinear behaviour of the beam, as expected. The effect is observed for both - i.e. the first (Fig. 7a) and second (Fig. 7b) coefficients of nonlinearity. The strongest nonlinear behaviour - exhibited by the second coefficient - was observed for the responses captured in the vicinity of the crack. The crack localisation effect cannot be observed when the second coefficient of nonlinearity is analysed.

Fig. 8a demonstrates the effect of the crack location on nonlinear responses. Here, the strongest nonlinear behaviour can be observed near the crack vicinity when the crack is located closer to the fixed end (200 mm from the free end). Clearly, the nonlinearity is enhanced and localised near the damage. The amplitude of the second harmonic decreases towards the free and fixed ends of the beam. In contrast, when the crack is located closer to the free end of the beam, the strongest level of nonlinearity can be observed near the fixed end of the beam.

Additionally, a beam with two cracks was studied. Two different configurations were considered: (1) 200 and 150 mm; (2) 200 and $100 \mathrm{~mm}$ from the free end. The depth of all the cracks is $6 \mathrm{~mm}$. The results are given in Fig. $8 \mathrm{~b}$. For each of considered configurations two peaks in the amplitude of second harmonic are observed. First of these peaks is at the exactly same location for both configurations, i.e. about $200 \mathrm{~mm}$ from the free end of the beam. A location of the second peak is different for each configuration. In the first configuration, the second peak is exactly at the crack position - i.e. 150 mm from the free end. In the second configuration, the peak is closer to the free end of a beam (about 120-130 mm from the free end, while the crack is located $100 \mathrm{~mm}$ from free end). The nonlinearity coefficient is much stronger in the vicinity of the crack located closer to the fixed end of the beam than for that closer to the free end of the beam. According to these results it might be concluded, that the amplitude of second harmonic might be a good indicator of crack location even when there is more than one crack in a single beam. However, precision of localisation depends on the crack position. In the investigated scenarios, the crack was localised precisely for the first configuration, but some discrepancies were observed for the second one.

In summary, the following observations can be made. There is no single location of sensor on the beam that would be able to localise the crack. Several measurements on the beam are needed to achieve this goal. Generally, cracks that are located near the fixed end of the beam enhance the nonlinear effect and, therefore, crack localisation can be achieved. The level of nonlinearity near the crack decreases with the distance between the crack and the fixed end. In the majority of 
(a)

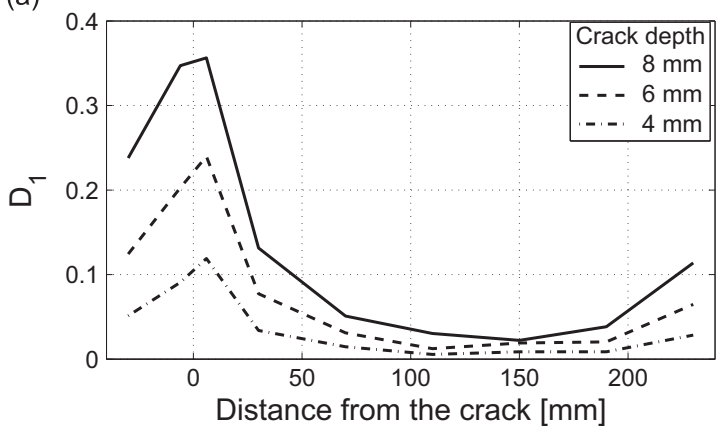

(b)

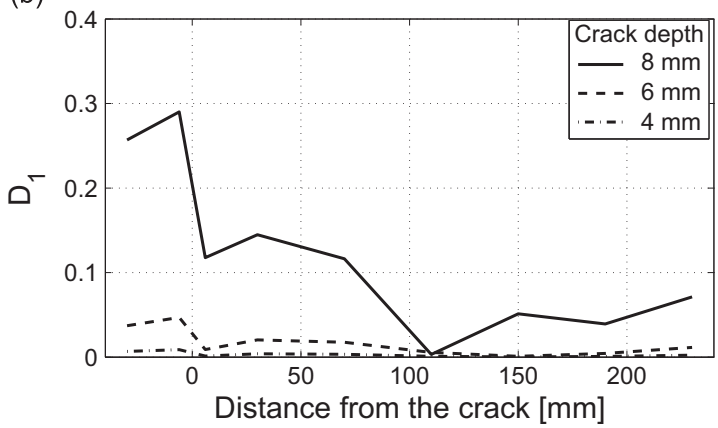

Fig. 7. Crack-depth study for breathing crack model (the crack was located $250 \mathrm{~mm}$ from the free end of the beam). Nonlinear behaviour was investigated using (a) first coefficient of nonlinearity; (b) second coefficient of nonlinearity.

(a)

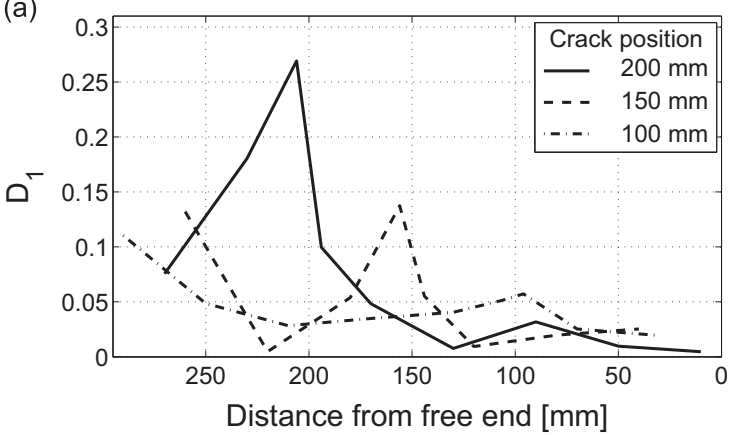

(b)

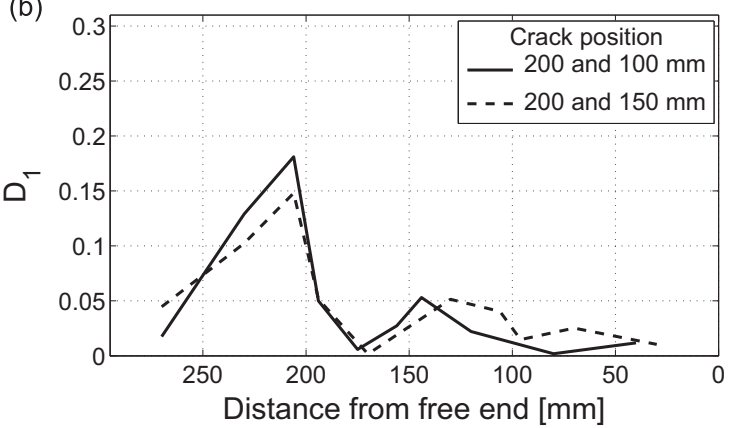

Fig. 8. Crack location study for breathing crack model - (a) single crack and (b) two cracks. The crack position given in the legend is its distance from the free end of the beam.

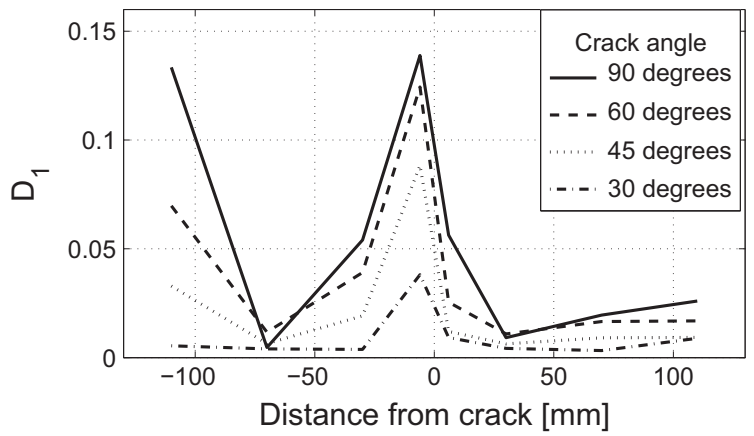

Fig. 9. First coefficient of nonlinearity for various orientations of the slant crack. The position of the crack is marked with a thick, black line.

investigated models, cracks positioned closer to the fixed end (i.e. far away from the excitation) exhibit stronger nonlinear behaviour than near the free end of the beam.

\subsection{Crack depth and localisation for slant and internal crack}

This section presents numerical simulation results for the nonlinear longitudinal vibration of beams with slant cracks. Fig. 9 demonstrates the effect of orientation of the slant crack that affects the nonlinear behaviour of the beam. The amplitude of the second harmonic for the 8-mm-long crack - located in the middle of the beam - was investigated in these studies. The location of the slant crack refers to the position of its notch's root and its angle refers to the angle between the crack and the top surface of the beam. The results show that the nonlinearity exhibited by the slant crack is also significantly enhanced in the vicinity of the crack. Interestingly, the nonlinear effect near the fixed end of the beam becomes stronger with increasing crack angles. The level of nonlinearity near the fixed end of the beam is almost the same as in the vicinity of the crack for the perpendicular crack. 


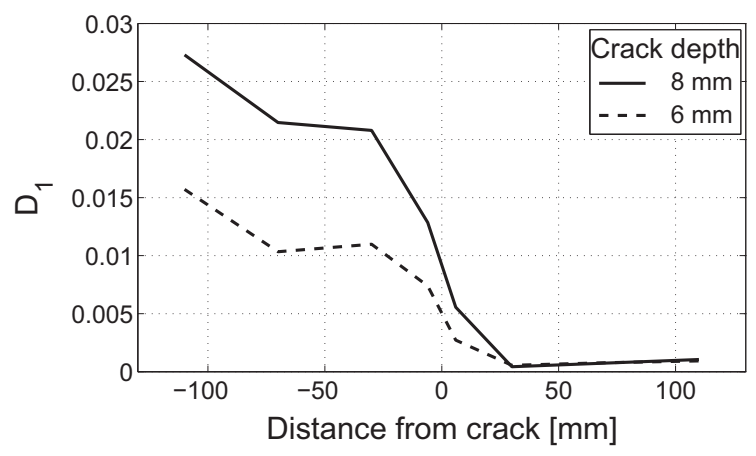

Fig. 10. First coefficient of nonlinearity for various depth of the internal crack.

Table 1

Numerical simulation parameters of beam.

\begin{tabular}{llc}
\hline Parameter & Unit & Value \\
\hline Modulus of elasticity & $\mathrm{Pa}$ & $70 \times 10^{9}$ \\
Density & $\mathrm{kg} / \mathrm{m}^{3}$ & 2700 \\
Poisson ratio & - & 0.33 \\
Longitudinal stiffness & $\mathrm{kg} / \mathrm{m}$ & $4.66 \times 10^{7}$ \\
Normal contact stiffness & $\mathrm{kg} / \mathrm{m}$ & $70 \times 10^{11}$ \\
First longitudinal natural frequency & $\mathrm{Hz}$ & 4248 \\
\hline
\end{tabular}

The internal crack was also investigated in numerical simulations. The crack was located in the middle of the beam, i.e. $150 \mathrm{~mm}$ from the fixed end of the beam. The crack was perpendicular to the top and bottom surfaces of the beam. The internal crack investigated was positioned symmetrically with respect to the top and bottom surfaces of the beam, i.e. the centre of this internal crack was $12.5 \mathrm{~mm}$ from the top surface of the beam. Therefore, in contrast to the edge crack that breaks the symmetry of the vibrated structure, the symmetry of the beam with the investigated internal crack is not broken. Two sizes of the internal crack - i.e. 6 and $8 \mathrm{~mm}$ - were investigated. The results - presented in Fig. 10 - demonstrate that the internal crack introduces much weaker nonlinearities to longitudinal vibration responses of the beam. Also, in contrast to the orthogonal and slant edge cracks investigated, crack localisation is not possible for the internal crack. The largest amplitude of the second harmonic can be observed near the fixed end of the beam. This amplitude decreases nearly monotonically towards the free end of the beam. The level of nonlinearity depends on the crack size, as expected.

\subsection{Simplified crack modelling}

Two simplified crack models were compared with the breathing crack model. Both models are based on the nonlinear stress-strain function. Higher-order terms in the stress-strain function were considered in the first simplified model; the bilinear elasticity was used in the second model. In order to investigate the crack localisation effect, only a small part of a beam (in the vicinity of the crack) was modelled using a nonlinear material model. The nonlinear part of the beam was modelled using hypoelastic material properties with the supplied nonlinear constitutive equation. The rest of the beam was modelled using linear material properties given in Table 1. Both simplified models were built in the MSC Marc commercial software. The beam was meshed with 2-D plane stress, full integration elements.

Results of numerical simulations for the model based on the second-order term in the stress-strain function are given in Fig. 11. The first coefficient of nonlinearity is investigated in Fig. 11a for three different levels of input excitation. The results show that the crack localisation effect strongly depends on the level of excitation. However, for various crack positions investigated in Fig. 11b, the crack localisation effect is rather weak; it is not easy to locate the crack position using the first coefficient of nonlinearity.

Numerical simulation results for crack localisation for the bi-linear model are presented in Fig. 12. The results demonstrate that the crack can be localised using the first coefficient of nonlinearity. Thus the results based on the bi-linear elasticity crack model are consistent with those obtained using the breathing crack model.

In summary, the simplified crack model based on the bi-linear elasticity corresponds well to the breathing crack model (based on the contact between crack faces). Both models represent the crack localisation effect quite well when the second coefficient of elasticity is investigated. The high level of nonlinearity in the vicinity of the crack is connected to the sudden transition from the open to the closed crack. This sudden transition is distinctive for both - bi-linear and breathing - crack models. 
(a)

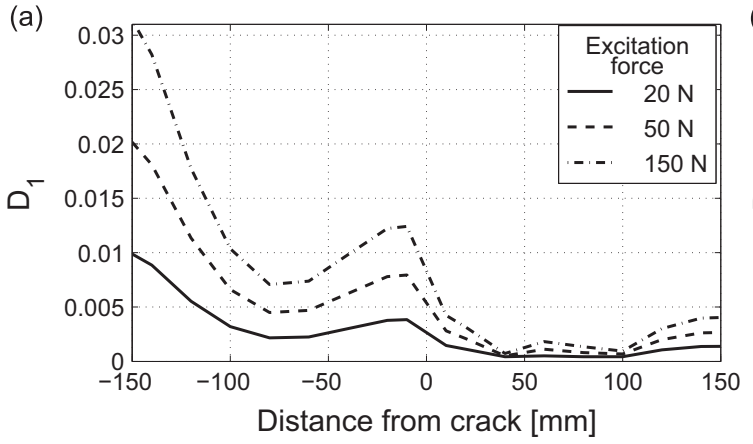

(b)

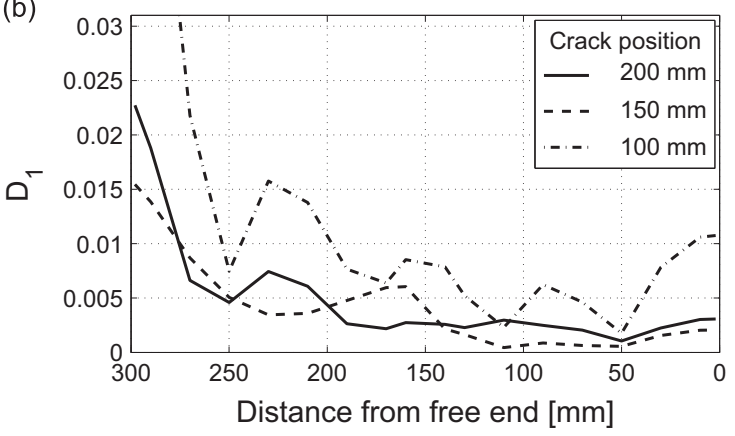

Fig. 11. Numerical simulation results for simplified crack model based on second-order term in constitutive equation. First coefficient of nonlinearity for various: (a) input excitation levels; (b) crack locations. Crack position given in the legend is its distance from the free end of the beam.

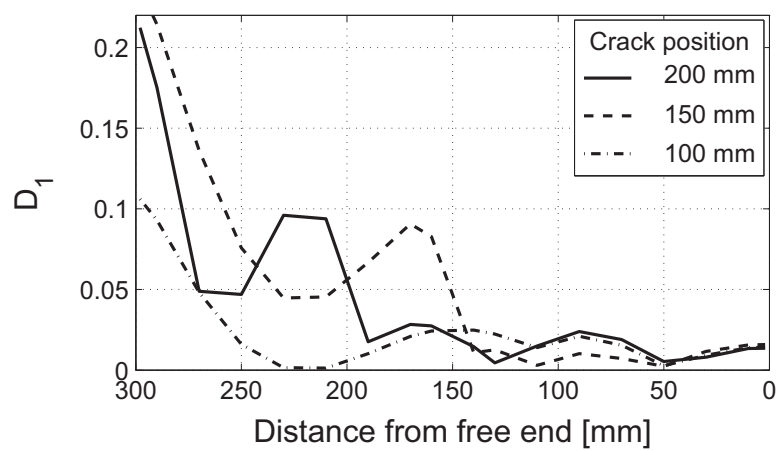

Fig. 12. Numerical simulation results for simplified crack model based on bi-linear elasticity. The first coefficient of nonlinearity is investigated for various crack locations. Crack position given in the legend is its distance from the free end of the beam.

\section{Experimental validation}

A series of experiments was undertaken in order to validate the numerical simulation results presented in Section 3. Nonlinear behaviour of cracked beams was investigated for different crack depths and locations as well as different sensor positions and boundary conditions.

\subsection{Experimental set-up and procedure}

The $300 \times 20 \times 10 \mathrm{~mm}$ beams, made of aluminium grade $6082 \mathrm{~T} 6$, were used as test samples in all experimental investigations. The height of the beam had to be reduced if compared with numerical simulations - to comply with the available experimental fatigue testing facilities. Cracks were initiated in the beams using a wire-cut Electric Discharge Machining (EMD) system. A three-point bending fatigue test was performed to propagate cracks in the beam to desired depths. Fig. 13 shows a zoomed part of the intact and cracked beams.

The cracked beams were tested to obtain their vibration responses. The beams were either clamped or freely hanged to maintain the fixed-free and free-free boundary conditions, respectively. The $50 \mathrm{~mm}$ part of one end of the beam was clamped using a heavy hydraulic vice in the fixed-free boundary condition arrangement. A constant clamping force was maintained in all experimental tests. Two different crack depths -4 and $10 \mathrm{~mm}$ and two different crack locations 100 and $15 \mathrm{~mm}$ from the free end of the beam - were investigated. Altogether three vibration tests were performed, as summarised in Table 2.

Low-profile, surface-bonded Noliac NCE5 monolayer piezoceramics discs ( $5 \mathrm{~mm}$ diameter; $1 \mathrm{~mm}$ thickness) were used to measure vibration responses. Five piezoceramic sensors were bonded to the top surface of the beam (i.e. the surface where the cracks were introduced) using Loctite 401 cyanoacrylate glue. Two sensors were bonded close to both ends of a beam, two sensors were positioned near the crack and one sensor was bonded in the middle between the crack and the fixed end. The beam was excited using two different sources - TMS K2007E01 electromagnetic shaker and Noliac NAC2014-A01 piezoceramic multilayer plate actuator. A schematic diagram illustrating the geometry of the cracked beam and positions of sensors/actuators is given in Fig. 14.

The positions of sensors for a beam with a crack at $100 \mathrm{~mm}$ from the excitation are shown in Table 3.

An EC Systems PAQ-G single-channel system was used for signal generation and data acquisition. All vibration responses were post-processed in MATLAB to obtain response spectra and nonlinear coefficients, following the procedure described in Section 2. 
(a)

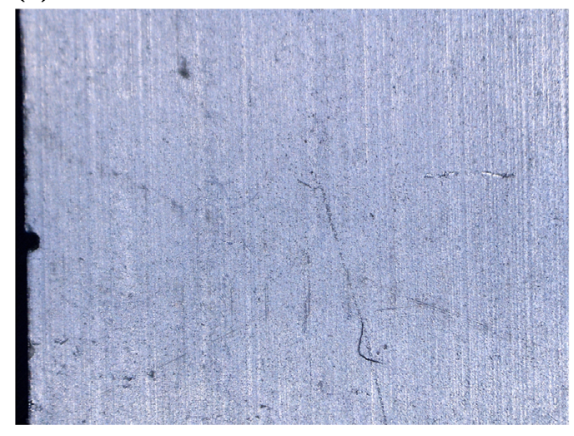

(b)

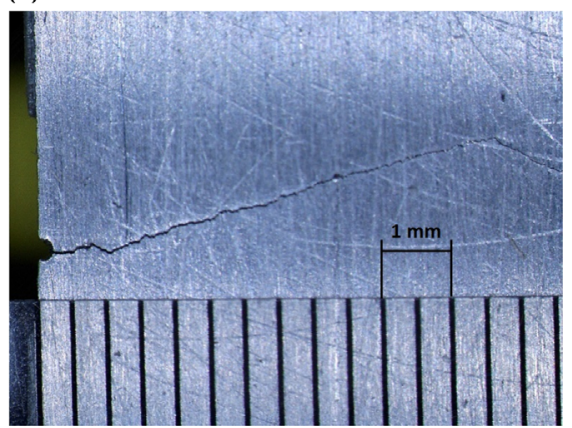

Fig. 13. Microscopic photographs of beams: (a) intact condition; (b) fatigue crack under static tension load.

Table 2

Crack depths and positions investigated in experimental tests.

\begin{tabular}{lll}
\hline Experimental test & Crack depth $(\mathbf{m m})$ & Crack position (mm) \\
\hline 1 & 10 & 100 \\
2 & 9 & 100 \\
3 & 9 & 150 \\
\hline
\end{tabular}

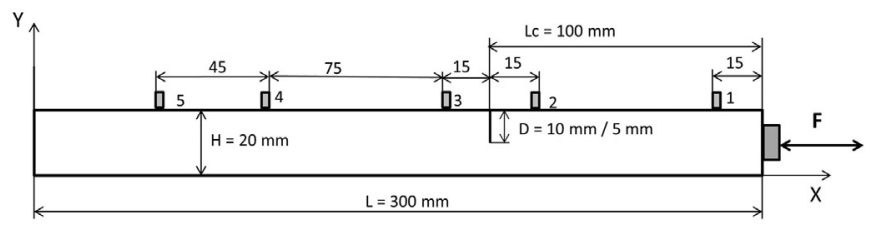

Fig. 14. Scheme of tested beam with crack located $100 \mathrm{~mm}$ from excitation.

\subsection{Natural frequency shifts}

Experimental modal analysis was performed to find natural frequencies of the beams excited using sweep sine excitation. The fundamental natural frequency for the longitudinal vibration of the intact clamped beam was found to be $4037 \mathrm{~Hz}$. This frequency reduced to $3951 \mathrm{~Hz}$ for the cracked beam.

A similar modal test was performed for a freely supported beam. The fundamental natural frequency for longitudinal vibration of this beam was estimated as $8435 \mathrm{~Hz}$.

Table 4 summarises crack-related changes to natural frequencies. According to the obtained data, the natural frequency shift is higher for free-free BC for experimental test 1 . In experimental test 3 the crack was located in the node of vibration in free-free BC. This way, the natural frequency shift was higher for fixed-free, than free-free BC.

\subsection{Higher harmonic generation}

A series of experimental tests were performed to investigate crack-related higher harmonic generation; various amplitude levels of excitation were used in these tests. Vibration damping in cracked beams was significantly higher than in intact beams, resulting in much lower amplitude levels of vibration responses. In order to minimise the influence of boundary conditions, the level of excitation amplitude was always selected to obtain similar amplitude levels of vibration responses for the intact and cracked beams. In order to satisfy this condition, four different input amplitudes were selected, for which the maximum amplitude of vibration responses for the first longitudinal vibration mode captured by sensor 4 reached the levels of $0.5,2.0,5.0$ and $7.5 \mathrm{~V}$, respectively.

In order to compare the results obtained for different input amplitudes, the coefficient of nonlinearity was calculated using Eq. (4). Crack-related higher harmonic generation was investigated not only for different excitation amplitudes but also for different crack depths and locations as described in Section 4.1.

Three initial response measurements were taken in each experimental test in order to assess the repeatability of the results. Those measurements will be referred to as measurements 1,2 and 3, respectively. The beams were disassembled after each measurement.

The probability of crack detection was assessed on the basis of a worst case scenario measurements - i.e. considering the highest amplitudes found for intact beams, and the lowest amplitudes found for cracked beams. 
Table 3

Position of sensors (distance from excitation) for beam with crack at $150 \mathrm{~mm}$ from excitation.

\begin{tabular}{lllll}
\hline Sensor no. & $\mathbf{1}$ & $\mathbf{2}$ & $\mathbf{3}$ & $\mathbf{4}$ \\
\hline Distance from excitation point $(\mathrm{mm})$ & 15 & 75 & 135 \\
\hline
\end{tabular}

Table 4

Frequency shifts due to fatigue cracks.

\begin{tabular}{lll}
\hline Experimental test & Boundary condition & Natural frequency shift $($ Hz) \\
\hline 1 & Fixed-free, shaker excitation & 86 \\
1 & Fixed-free, piezo excitation & 89 \\
1 & Free-free, piezo excitation & 330 \\
3 & Fixed-free, shaker excitation & 106 \\
3 & Free-free, piezo excitation & 81 \\
2 & Fixed-free, shaker excitation & 66 \\
\hline
\end{tabular}

(a)

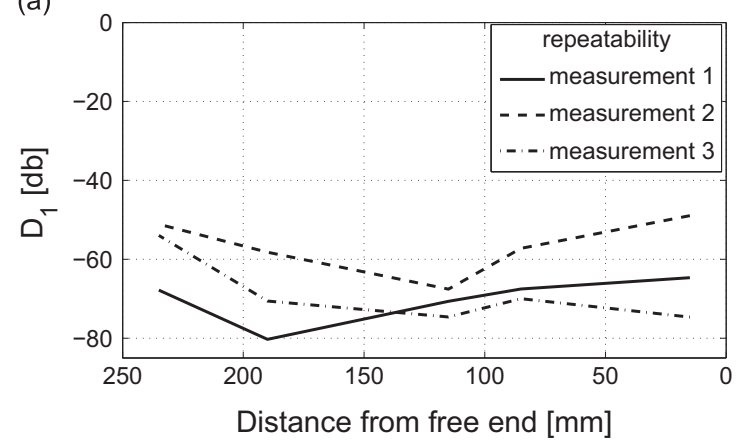

(b)

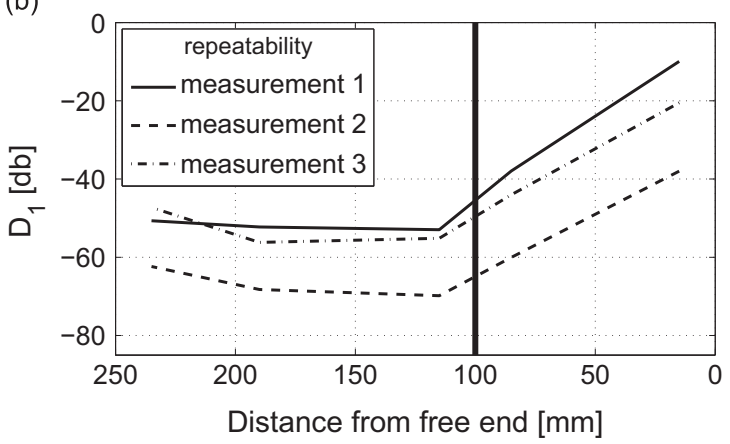

Fig. 15. Repeatability study, each consisting of 3 measurements: (a) intact beam; (b) cracked beam in experimental test 1 , as described in Table 2 . The position of the crack is marked with a vertical, solid black line.

\subsubsection{Crack detection}

In the first test, the cracked beam in experimental test 1 was compared with the intact beam. The repeatability study for this comparison is shown in Fig. 15. According to the presented results the crack presence might be detected only at the sensor near the free end of a beam. At the remaining sensor, amplitudes of second harmonic might be lower at cracked, than at intact, beam.

It should be also stressed that the repeatability in results obtained for cracked beam is poor only if amplitude at single sensor is taken into consideration. The repeatability is much better if, instead of amplitude alone, its distribution along the beam is taken into consideration. In each measurement the second harmonic is low between the clamped end of a beam and crack. Once the crack position is exceeded, the nonlinearity level increases (i.e. at sensors 85 , and $15 \mathrm{~mm}$ from the free end of a beam).

It has been investigated whether the second harmonic increases near the free end of a beam also in other experimental tests. Results are shown in Fig. 16. In both experimental test 2 (Fig. 16a) and experimental test 3 (Fig. 16b), the significant increase of second harmonic near the free end of a beam was observed.

There are pronounced differences between results obtained in simulations and in experiments. In the former, the nonlinearity was high near the fixed end of a beam, while no increase at the free end was observed.

\subsubsection{Crack localisation}

Localisation of the crack is not possible on the basis of amplitude of harmonics, measured at a single location, alone, as was shown in the previous section. According to Figs. 15 and 16, the potential growth of nonlinearity in the vicinity of the crack is masked by a very high amplitude of harmonics near the excitation end.

In Fig. 17 the nonlinearity coefficients calculated for sensors located $75-230 \mathrm{~mm}$ from the free end of the beam are shown (i.e. without the sensor mounted at the free end of the beam). Results of repeatability tests performed for the beam in experimental test 1 are shown in Fig. 17a, and for the beam in experimental test 3 in Fig. 17b. In those configuration the crack position is different (Table 3 ).

Although the amplitudes are similar for both tests, there are differences in distribution of higher harmonics amplitude along the beam. The results in Fig. 17a show that the level of nonlinearity started to increase near the crack (i.e. 100 mm 
(a)

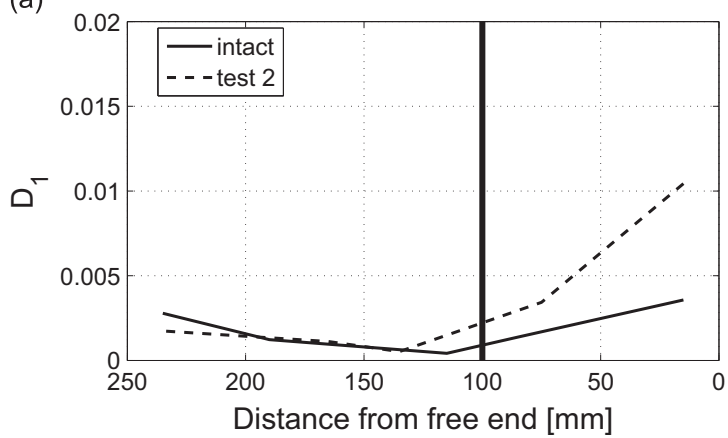

(b)

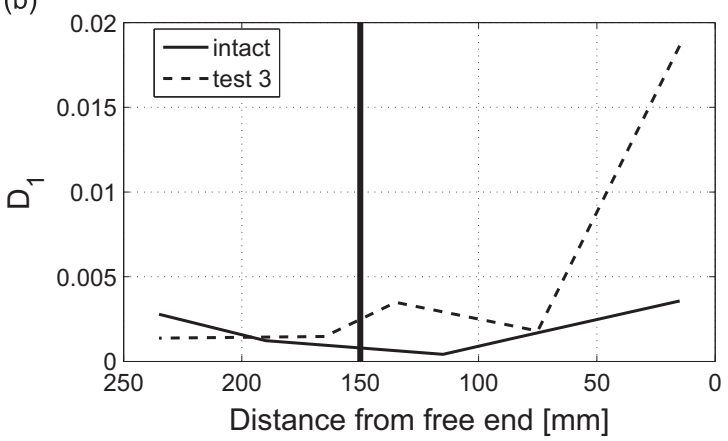

Fig. 16. First nonlinearity coefficient for intact and cracked beam in (a) experimental test 2; (b) experimental test 3 , as described in Table 2. The position of the crack is marked with a vertical, solid black line at each plot.

(a)

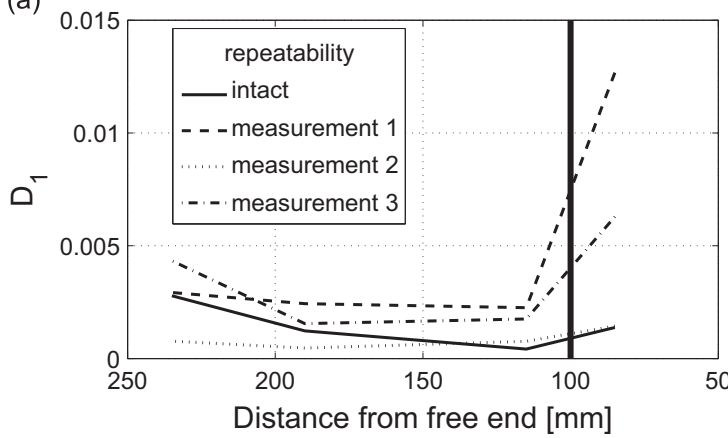

(b)

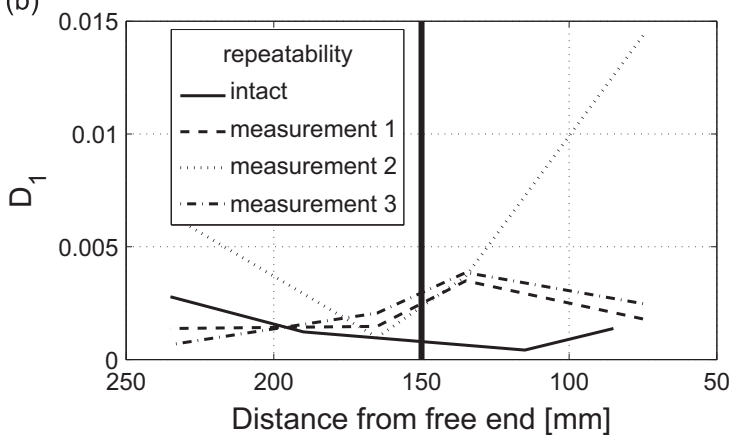

Fig. 17. Repeatability study, each consisting of 3 measurements: (a) cracked beam in experimental test 1 ; (b) cracked beam in experimental test 3 , as described in Table 2. In each plot, a single measurement performed on intact beam is shown. The position of the crack is marked with a vertical, solid black line at each plot.

from the free end of the beam) when the test 1 was performed. Such a trend is clear even in measurement 2 , where the amplitudes of second harmonics are at the similar level, as in the intact beam.

Similar but slightly weaker-behaviour can be observed in the experimental test 3 (the crack positioned $150 \mathrm{~mm}$ from the fixed end, Fig. 17b). There are, however, differences between the consecutive measurements in test 3 . Namely, in the measurement 2 the extent of nonlinearity starts to increase at the crack location and continues to the free end of the beam. In the two remaining measurements, there is a decrease of nonlinearity at about 100 mm from the excitation point. However, in all three measurements the increase of nonlinearity just before the crack was observed.

\section{Conclusions}

Nonlinear, longitudinal vibration of beams with breathing cracks was investigated. The study was focused on modelling of crack-induced, localised growth of nonlinearity, i.e. the so-called crack localisation effect. Various crack models were analysed, including those based on the second order term in elastic moduli, bi-linear stiffness and breathing crack. Numerical simulations were performed using two-dimensional finite elements. Simulation results were validated experimentally using aluminium cracked beams. Various crack depths, locations and boundary conditions were investigated. The main focus of the work presented was on crack localisation.

The obtained results demonstrate that crack localisation based on higher harmonic generation is possible when longitudinal vibration of beams is investigated: the amplitude of higher harmonics increases in the vicinity of the crack. Numerical simulation results show that this crack localisation effect is particularly strong when the breathing and bi-linear elasticity crack models are used. The results also revealed strong nonlinear effects in the region of the fixed end of the beam. The experimental results also demonstrated that the level of nonlinearity depended on a sensor location. However, the latter dependence is not as simple as in numerical simulations.

The numerical FE model of the breathing crack was capable to capture most of nonlinear phenomena found in the experiments. However, the localisation effect was much weaker in the experiments than in numerical simulations. The actual distribution of amplitude of higher harmonics alongside the beam, found in the experimental investigations, was not captured properly by any of the tested FE models. The model based on the second order elastic term was the only one capable to reflect properly the relation between the excitation amplitude and the measured level of nonlinearity. 
In summary, the most important conclusions that can be drawn from the presented work are:

- The FE model of beams with breathing cracks revealed that the strongest crack localisation effect was based on second harmonic generation.

- The strongest crack localisation effect was observed in experiments when the fixed-free boundary conditions were investigated.

- Crack detection in cantilever beams is only possible when nonlinear vibration is investigated near their free (excited) end.

- Longitudinal vibration amplitudes of higher harmonics enables the detection of cracks experimentally only if the excitation level is high enough to start the crack closing-opening action.

Although the presence of crack localisation effect was confirmed in experiments, its level was very low. For complex structures, there is a need for further investigation which includes non-contact measurements or optimal deployment of the sensors. It should be, however, noted that in the longitudinal vibration the level of crack perturbation was much smaller than in the transversal vibration studied in previous investigations. Therefore further work should focus on transversal vibration of beams. Also, FE modelling of beams with breathing crack should be further developed in order to properly represent the experimental results.

\section{Acknowledgement}

The work presented in this paper was supported by The Foundation for Polish Science under the research WELCOME Project no. 2010-3/2. The program operated within The Innovative Economy Operational Programme 2007-2013.

\section{References}

[1] P.O. Moore (Ed.), Nondestructive Testing Handbook, 3rd edition, Vol. 10. Overview, American Society for Nondestructive Testing, Columbus, OH, USA 2012

[2] C. Boller, F.-K. Chang, Y. Fujino, Encyclopedia of Structural Health Monitoring, Vol. 2960, Wiley, New York, NY, USA, 2009.

[3] C. Staszewski, Tomlinson Boller G. (Eds.), Health Monitoring of Aerospace Structures: Smart Sensor Technologies, John Wiley \& Sons, Chichester, UK, 2004.

[4] M.F. Hamilton, D.T. Blackstock, Nonlinear Acoustics, Academic Press, Melville, NY, USA, 1998.

[5] P.P. Delsanto (Ed.), Universality of Nonclassical Nonlinearity: Applications to Non-destructive Evaluations and Ultrasonics, Springer, New York, USA, 2006.

[6] T. Stepinski, T. Uhl, W.J. Staszewski (Eds.), Advanced Structural Damage Detection: From Theory to Engineering Applications, Wiley, Chichester, UK, 2013.

[7] V.Y. Zaitsev, A. Sutin, I.Y. Belyaeva, V. Nazarov, Nonlinear interaction of acoustical waves due to cracks and its possible usage for cracks detection, Journal of Vibration and Control 1 (3) (1995) 335-344, http://dx.doi.org/10.1177/107754639500100305.

[8] P.B. Nagy, Fatigue damage assessment by nonlinear ultrasonic materials characterization, Ultrasonics 36 (1) (1998) $375-381$.

[9] P.A. Johnson, The new wave in acoustic testing, Materials World (1999) 544-546.

[10] P. Cawley, R.D. Adams, The location of defects in structures from measurements of natural frequencies, The Journal of Strain Analysis for Engineering Design 14 (2) (1979) 49-57, http://dx.doi.org/10.1243/03093247V142049.

[11] A.D. Dimarogonas, Vibration of cracked structures: a state of the art review, Engineering Fracture Mechanics 55 (5) (1996) 831-857, http://dx.doi.org/ 10.1016/0013-7944(94)00175-8.

[12] P. Gudmundson, The dynamic behaviour of slender structures with cross-sectional cracks, Journal of the Mechanics and Physics of Solids 31 (4) (1983) 329-345, http://dx.doi.org/10.1016/0022-5096(83)90003-0.

[13] A. Ibrahim, F. Ismail, H. Martin, Modelling of the dynamics of continuous beam including nonlinear fatigue crack, Journal of Analytical, Experimental Modal Analysis 2 (1987) 76-82.

[14] T. Chondros, A. Dimarogonas, J. Yao, A continuous cracked beam theory, Journal of Sound and Vibration 215 (1) (1998) 17-34, http://dx.doi.org/10.1006/ jsvi.1998.1640.

[15] P. Rizos, N. Aspragathos, A. Dimarogonas, Identification of crack location and magnitude in a cantilever beam from the vibration modes, Journal of Sound and Vibration 138 (3) (1990) 381-388, http://dx.doi.org/10.1016/0022-460X(90)90593-0.

[16] M. Krawczuk, W. Ostachowicz, Modelling and vibration analysis of a cantilever composite beam with a transverse open crack, Journal of Sound and Vibration 183 (1) (1995) 69-89, http://dx.doi.org/10.1006/jsvi.1995.0239.

[17] F. Ismail, A. Ibrahim, H. Martin, Identification of fatigue cracks from vibration testing, Journal of Sound and Vibration 140 (2) (1990) 305-317, http://dx. doi.org/10.1016/0022-460X(90)90530-D.

[18] M. Chati, R. Rand, S. Mukherjee, Modal analysis of cracked beam, Journal of Sound and Vibration 207 (2) (1997) 249-270, http://dx.doi.org/10.1006/ jsvi.1997.1099.

[19] T. Chondros, A. Dimarogonas, J. Yao, Longitudinal vibration of a bar with a breathing crack, Engineering Fracture Mechanics 61 (56) (1998) 503-518, http://dx.doi.org/10.1016/S0013-7944(98)00077-0.

[20] T. Chondros, A. Dimarogonas, J. Jao, Vibration of a beam with a breathing crack, Journal of Sound and Vibration 239 (1) (2001) 57-67, http://dx.doi.org/ 10.1006/jsvi.2000.3156.

[21] A. Klepka, W. Staszewski, R. Jenal, M. Szwedo, J. Iwaniec, T. Uhl, Nonlinear acoustics for fatigue crack detection-experimental investigations of vibroacoustic wave modulations, Structural Health Monitoring 11 (2) (2012) 197-211, http://dx.doi.org/10.1177/1475921711414236.

[22] M. Krawczuk, Coupled longitudinal and bending forced vibration of Timoshenko cantilever beam with a closing crack, Journal of Theoretical and Applied Mechanics 32 (2) (1994).

[23] M. Friswell, J. Penny, A simple, nonlinear model of a cracked beam, 10th International Modal Analysis Conference, San Diego, California, 1992.

[24] R. Ruotolo, C. Surace, P. Crespo, D. Storer, Harmonic analysis of the vibrations of a cantilevered beam with a closing crack, Computers \& Structures 61 (6) (1996) 1057-1074, http://dx.doi.org/10.1016/0045-7949(96)00184-8.

[25] S. Doebling, C. Farrar, M. Prime, A summary review of vibration-based damage identification methods, Shock and Vibration Digest 30 (1998) $91-105$.

[26] A. Rivola, P. White, Bispectral analysis of the bilinear oscillator with application to the detection of fatigue cracks, Journal of Sound and Vibration 216 (5) (1998) 889-910, http://dx.doi.org/10.1006/jsvi.1998.1738.

[27] J.K. Sinha, Higher order coherences for fatigue crack detection, Engineering Structures 31 (2) (2009) 534-538, http://dx.doi.org/10.1016/j. engstruct.2008.10.004. 
[28] E. Douka, L. Hadjileontiadis, Time-frequency analysis of the free vibration response of a beam with a breathing crack, NDT E E International 38 (1) (2005) 3-10, http://dx.doi.org/10.1016/j.ndteint.2004.05.004.

[29] S. Loutridis, E. Douka, L. Hadjileontiadis, Forced vibration behaviour and crack detection of cracked beams using instantaneous frequency, NDT E E International 38 (5) (2005) 411-419, http://dx.doi.org/10.1016/j.ndteint.2004.11.004.

[30] A. Bovsunovsky, C. Surace, Considerations regarding superharmonic vibrations of a cracked beam and the variation in damping caused by the presence of the crack, Journal of Sound and Vibration 288 (45) (2005) 865-886, http://dx.doi.org/10.1016/j.jsv.2005.01.038.

[31] Z. Peng, Z. Lang, S. Billings, Crack detection using nonlinear output frequency response functions, Journal of Sound and Vibration 301 (35) (2007) 777-788, http://dx.doi.org/10.1016/j.jsv.2006.10.039.

[32] A. Chatterjee, Structural damage assessment in a cantilever beam with a breathing crack using higher order frequency response functions, Journal of Sound and Vibration 329 (16) (2010) 3325-3334, http://dx.doi.org/10.1016/j.jsv.2010.02.026.

[33] O. Giannini, P. Casini, F. Vestroni, Nonlinear harmonic identification of breathing cracks in beams, Computers and Structures 129 (2013) 166-177, http://dx.doi.org/10.1016/j.compstruc.2013.05.002.

[34] D. Dutta, H. Sohn, K.A. Harries, P. Rizzo, A nonlinear acoustic technique for crack detection in metallic structures, Structural Health Monitoring 8 (3) (2009) 251-262, http://dx.doi.org/10.1177/1475921709102105.

[35] A. Bouboulas, N. Anifantis, Finite element modeling of a vibrating beam with a breathing crack: observations on crack detection, Structural Health Monitoring 10 (2) (2011) 131-145, http://dx.doi.org/10.1177/1475921710373286.

[36] A. Bouboulas, N. Anifantis, Three-dimensional finite element modeling of a vibrating beam with a breathing crack, Archive of Applied Mechanics 83 (2) (2013) 207-223, http://dx.doi.org/10.1007/s00419-012-0647-z.

[37] S. Orhan, Analysis of free and forced vibration of a cracked cantilever beam, NDT E E International 40 (6) (2007) 443-450, http://dx.doi.org/10.1016/j. ndteint.2007.01.010.

[38] M. Krawczuk, M. Palacz, W. Ostachowicz, The dynamic analysis of a cracked Timoshenko beam by the spectral element method, Journal of Sound and Vibration 264 (5) (2003) 1139-1153.

[39] U. Andreaus, P. Casini, F. Vestroni, Non-linear dynamics of a cracked cantilever beam under harmonic excitation, International Journal of Non-Linear Mechanics 42 (3) (2007) 566-575, http://dx.doi.org/10.1016/j.ijnonlinmec.2006.08.007.

[40] U. Andreaus, P. Baragatti, Cracked beam identification by numerically analysing the nonlinear behaviour of the harmonically forced response, Journal of Sound and Vibration 330 (4) (2011) 721-742, http://dx.doi.org/10.1016/j.jsv.2010.08.032.

[41] U. Andreaus, P. Baragatti, Experimental damage detection of cracked beams by using nonlinear characteristics of forced response, Mechanical Systems and Signal Processing 31 (2012) 382-404, http://dx.doi.org/10.1016/j.ymssp.2012.04.007.

[42] V. Hiwarkar, V. Babitsky, V. Silberschmidt, V. Hiwarkar, V. Babitsky, V. Silberschmidt, On the modelling of dynamic structures with discontinuities, Nonlinear Dynamics 67 (4) (2012) 2651-2669, http://dx.doi.org/10.1007/s11071-011-0178-0.

[43] V. Hiwarkar, V. Babitsky, V. Silberschmidt, V.R. Hiwarkar, V.I. Babitsky, V.V. Silberschmidt, Crack as modulator, detector and amplifier in structural health monitoring, Journal of Sound and Vibration 331 (15) (2012) 3587-3598, http://dx.doi.org/10.1016/j.jsv.2012.03.009.

[44] V. Hiwarkar, V. Babitsky, V. Silberschmidt, Damage assessment of a cracked bar: effect of material nonlinearity on vibro-impact response, Key Engineering Materials 413-414 (2009) 237.

[45] U. Polimeno, M. Meo, D. Almond, Smart nonlinear acoustic based structural health monitoring system, Advances in Science and Technology 56 (2008) 426-434.

[46] U. Polimeno, M. Meo, D. Almond, S. Angioni, Detecting low velocity impact damage in composite plate using nonlinear acoustic/ultrasound methods, Applied Composite Materials 17 (2010) 481-488.

[47] L. Pieczonka, A. Klepka, W. Staszewski, T. Uhl, Nonlinear Acoustic Imaging of Structural Damages in Laminated Composites, in: V. Le Cam, L. Mevel, F. Schoefs (Eds.), EWSHM-7th European Workshop on Structural Health Monitoring, IFSTTAR, Inria, Université de Nantes, Nantes, France, 2014.

[48] D. Broda, W. Staszewski, A. Martowicz, T. Uhl, V. Silberschmidt, Modelling of nonlinear crack-wave interactions for damage detection based on ultrasound-a review, Journal of Sound and Vibration 333 (4) (2014) 1097-1118. 